\title{
Exploration on Recycling of Waste Liquid COD by Potassium Dichromate Method
}

\author{
Jing-Ping Wang, Zheng-Hao Fei, Xin-Hong Wang, Jian Chen, Zong-Tang Liu \\ School of Chemical and Environmental Engineering, Yancheng Teachers University, \\ Jiangsu, 224007, China,
}

The research is supported by a Project Funded by the brand professional project form Yancheng teachers college (2016) and the teaching reform and practice of medicinal chemistry (2018YCTUJGY006) and the Flagship Major Development of Jiangsu Higher Education Institutions"(PPZY2015B113)。

Abstract

Potassium dichromate method was used to determine the high concentration of $\mathrm{Hg}^{2+}, \mathrm{Ag}^{+}, \mathrm{Cr}(\mathrm{VI}), \mathrm{Cr}^{3+}$ and $\mathrm{H}_{2} \mathrm{SO}_{4}$ in COD waste liquid. The waste liquid of COD was determined by potassium dichromate method, and the aluminum was used to replace $\mathrm{Ag}+$ in the waste liquid to generate $\mathrm{Ag}$ and precipitate out, $\mathrm{Cr}(\mathrm{VI})$ was reduced to $\mathrm{Cr}^{3+}$, and then alkali neutralization, filtration and other measures were added to carry out treatment and recovery of useful substances, which not only reduced environmental pollution, but also recovered resources, with both economic and environmental benefits.

Keywords Potassium dichromate method; Waste liquid; Reduction; Neutralization

DOI: $10.7176 / \mathrm{CER} / 11-10-08$

Publication date: November $30^{\text {th }} 2019$

\section{Introduction}

There are many methods to determine COD, including classical reflux method, spectrophotometry and coulomb method ${ }^{[1]}$. Among them, potassium dichromate method is a standard analysis method recognized at home and abroad (referred to as standard method), which is usually expressed by CODcr. Europe and the United States adopted CODcr method as the standard method for the determination of COD in water and wastewater, but the measurement accuracy was worse than that of clean water samples (COD $<50 \mathrm{~m} \mathrm{~g} / \mathrm{L}$ ). Only by the standard method in our country as a standard method for the determination of COD in wastewater ${ }^{[2-3]}$, standard method can be widely used for a long time, is because it has the following several advantages: 1 . The potassium dichromate chemical stability; 2. The oxidation rate of most organic compounds is relatively high, and the oxidation rate of general water samples is up to $90 \%$; 3 . The method has good reproducibility and high reliability; 4 . Wide application scope (suitable for various types of water samples, such as surface water, industrial wastewater and domestic sewage, etc.). Its shortcomings are as follows: 1. Digestion lasts for 2 hours, which is too long for conventional analysis; 2 . Use precious silver salt as catalyst, which has higher cost; 3. Complex Cl- with toxic mercuric sulfate can produce secondary environmental pollution; 4. Due to the large space occupied by reflux digestion, batch determination is difficult.

Due to the use of precious silver halide catalytic oxidation of volatile organic compounds, and use of toxic mercury sulfate complexing $\mathrm{Cl}$-, $\mathrm{CODCr}$ waste any emissions, will lead to $\mathrm{Ag}, \mathrm{H} \mathrm{g}$ and contains a lot of low $\mathrm{pH}$ value of waste liquid cause secondary pollution to environment, at the same time also brings great damage on the economy. In particular, mercury is easily converted into organic mercury (methyl mercury or dimethyl mercury) when it is discharged into the environment. It accumulates rapidly after entering the food chain and has a strong biological toxicity, so it also causes potential harm to human health. Some laboratories even did not make treatment, will be discharged into the sewer, some simply with alkali neutralization and back into the sewer, or collection buried underground. In this way, it not only causes serious environmental pollution, but also wastes valuable resources such as silver, so the disposal of waste liquid is also a major problem worthy of attention ${ }^{[4-7]}$. In this paper, the COD waste liquid is measured, through reduction, neutralization and other measures, the treatment and the recovery of useful substances, not only reduce the pollution of the environment, but also the recovery of resources, with economic and environmental benefits.

\section{Correlation reaction of COD measurement}

According to the relevant standards for CODcr determination in China's water samples (GB-3838-2002), a certain amount of water samples to be measured were taken, and $\mathrm{H}_{2} \mathrm{SO}_{4}-\mathrm{Ag}_{2} \mathrm{SO}_{4}$ solution was added as a catalyst. A certain amount of potassium dichromate was used to oxidise the reducing substances in the water samples, and excessive potassium dichromate was used as an indicator of ferrous citric acid, and ammonium ferrous sulfate 
solution was used to drop back.

(1)Oxidation reaction (reflux reaction) :

$$
2 \mathrm{Cr}_{2} \mathrm{O}_{7}^{2-} \text { (excess) }+3 \mathrm{C}+16 \mathrm{H}^{+} \rightarrow 4 \mathrm{Cr}^{3+}+3 \mathrm{CO}_{2}+8 \mathrm{H}_{2} \mathrm{O}
$$

2)Drop back reaction:

$$
\mathrm{Cr}_{2} \mathrm{O}_{7}{ }^{2-} \text { (surplus) }+6 \mathrm{Fe}^{2+}+14 \mathrm{H}^{+} \rightarrow 2 \mathrm{Cr}^{3+}+6 \mathrm{Fe}^{3+}+7 \mathrm{H}_{2} \mathrm{O}
$$

3)Interference reaction of $\mathrm{Cl}^{-}$:

$$
\begin{gathered}
\mathrm{Cr}_{2} \mathrm{O}_{7}^{2-}+6 \mathrm{Cl}^{-}+14 \mathrm{H}^{+} \rightarrow 2 \mathrm{Cr}^{3+}+3 \mathrm{Cl}_{2}+7 \mathrm{H}_{2} \mathrm{O} \\
\mathrm{Ag}^{+}+\mathrm{Cl}^{-} \rightarrow \mathrm{AgCl} \downarrow \\
\mathrm{Hg}^{2+}+4 \mathrm{Cl}^{-} \rightarrow\left[\mathrm{HgCl}_{4}\right]^{2-} \\
\mathrm{Cr}^{3+}+6 \mathrm{Cl}^{-} \rightarrow\left[\mathrm{CrCl}_{6}\right]^{3-}
\end{gathered}
$$

\section{Process flow of waste liquid treatment and resource recycling}

Add pure aluminum scrap into the waste liquid, stir to make the silver powder in the waste liquid sink, filter, and purify and recycle the silver powder. Filtrate is neutralized with ammonia, settled, filtered, filtrate is used as green fertilizer. Stir filter residue, add $\mathrm{NaOH}$, filter, filter residue drying and collect. The filtrate was $\mathrm{pH}$ adjusted with hydrochloric acid and mixed with alkaline aluminum chloride, which was used as sewage purification agent. The process flow was shown in figure 1.

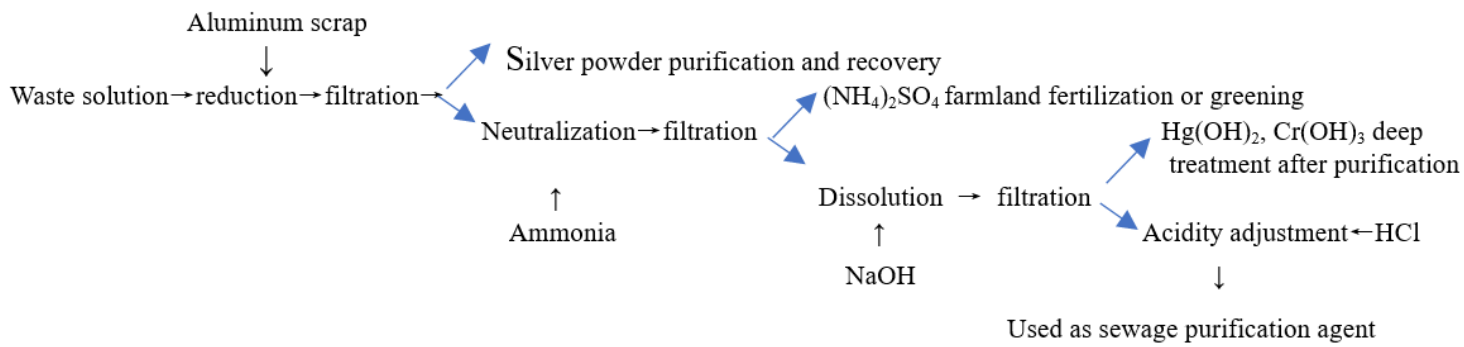

Figure 1 Process flow of waste liquid treatment

\section{Principle of waste liquid treatment and resource recovery}

Due to the strong reduction performance of $\mathrm{Al}, \mathrm{Ag}^{+}$and $\mathrm{Cr}(\mathrm{VI})$ are respectively reduced to $\mathrm{Ag}$ and $\mathrm{Cr}^{3+}$, and the reaction equation is as follows:

$$
\begin{aligned}
3 \mathrm{Ag}^{+}+\mathrm{Al} & =\mathrm{Ag}+\mathrm{Al}^{3+} \\
\mathrm{Cr}_{2} \mathrm{O}_{7}^{2-}+2 \mathrm{Al} & =2 \mathrm{Cr}^{3+}+2 \mathrm{Al}^{3+}+7 \mathrm{H}_{2} \mathrm{O}
\end{aligned}
$$

Filter the solution to recover the silver powder. $\mathrm{Al}^{3+}, \mathrm{Hg}_{2} \mathrm{SO}_{4} 、 \mathrm{Cr}^{3+}$ and $\mathrm{H}_{2} \mathrm{SO}_{4}$ were neutralized with ammonia water to obtain mixed precipitation of $\mathrm{Al}(\mathrm{OH})_{3}, \mathrm{Hg}(\mathrm{OH})_{2}$ and $\mathrm{Cr}(\mathrm{OH})_{3}$ and solution of $\left(\mathrm{NH}_{4}\right)_{2} \mathrm{SO}_{4}$. The reaction equation is as follows:

$$
\begin{gathered}
\mathrm{Al}_{2}\left(\mathrm{SO}_{4}\right)_{3}+6 \mathrm{NH}_{4} \mathrm{OH}=2 \mathrm{Al}(\mathrm{OH})_{3} \downarrow+3\left(\mathrm{NH}_{4}\right)_{2} \mathrm{SO}_{4} \\
\mathrm{Cr}_{2}\left(\mathrm{SO}_{4}\right)_{3}+6 \mathrm{NH}_{4} \mathrm{OH}=2 \mathrm{Cr}(\mathrm{OH})_{3} \downarrow+3\left(\mathrm{NH}_{4}\right)_{2} \mathrm{SO}_{4} \\
\mathrm{Hg}_{2} \mathrm{SO}_{4}+2 \mathrm{NH}_{4} \mathrm{OH}=\mathrm{Hg}(\mathrm{OH})_{2} \downarrow+\left(\mathrm{NH}_{4}\right)_{2} \mathrm{SO}_{4} \\
\mathrm{H}_{2} \mathrm{SO}_{4}+2 \mathrm{NH}_{4} \mathrm{OH}=\left(\mathrm{NH}_{4}\right)_{2} \mathrm{SO}_{4}+2 \mathrm{H}_{2} \mathrm{O}
\end{gathered}
$$

After filtration of the above reaction solution, the filtrate containing $\left(\mathrm{NH}_{4}\right)_{2} \mathrm{SO}_{4}$ can be used for fertilizing farmland or greening flowers and plants.

Mixed filtrates of $\mathrm{Al}(\mathrm{OH})_{3} 、 \mathrm{Hg}(\mathrm{OH})_{2}$ and $\mathrm{Cr}(\mathrm{OH})_{3}$ were treated with dilute $\mathrm{NaOH}$, and $\mathrm{Al}(\mathrm{OH})_{3}$ was dissolved, and the reaction equation was as follows:

$$
\mathrm{Al}(\mathrm{OH})_{3} \downarrow+\mathrm{NaOH}=\mathrm{NaAlO}_{2}+2 \mathrm{H}_{2} \mathrm{O}
$$

As $\mathrm{Hg}(\mathrm{OH})_{2}$ and $\mathrm{Cr}(\mathrm{OH})_{3}$ still exist as solids under appropriate $\mathrm{pH}$ conditions, the $\mathrm{pH}$ value of the solution is controlled, filtered, separated, dried and collected, and further treatment is entrusted to qualified units. $\mathrm{NaAlO}_{2}$ in the solution is adjusted to an appropriate acidity with hydrochloric acid, and then mixed with basic aluminum chloride, which can be used as sewage purification agent.

\section{Operation steps of waste liquid treatment}

(1) Put an appropriate amount of pure aluminum chips (waste aluminum wires can be cut) in an acid-resistant plastic bucket, and then filter the waste liquid after each test into the bucket and let it react by itself. After the reaction started, the aluminum chip surface gradually formed a layer of gray spongy silver powder, floating in the 
liquid level, stirring and dispersing and then sinking.

(2) After a bucket of waste liquid is restored (the aluminum wire is no longer used for reaction, at this time, the cl-containing solution does not generate white precipitation, but the solution is light blue), stir it fully, make the silver powder sink completely, suck out most of the liquid with siphon, filter the remaining waste liquid, and wash it with $0.1 \%$ sulfuric acid for 3-5 times. Collect siphon liquid, filtrate and washing liquid as liquid a.

(3) Remove silver powder, placed in the appropriate container, add 5\% 10\% NaOH solution soaked, and fully mixing, soak for several hours, when soaking about all night, to no longer bubbled, stating that the excess of aluminum is dissolved completely, remove the filter, with $0.1 \% \mathrm{NaOH}$ washing $3 \sim 5$ times, and then use clean water to $\mathrm{pH}$ to 7 , drying collection (if you want to get high purity silver powder, the increasing number of caustic washing, to can't check out the $\mathrm{Al}^{3+}$ ). At the same time, filtrate and washing liquid were collected as liquid $\mathrm{b}$.

(4) Stir liquid a, slowly neutralize it with $1: 5$ ammonia solution to a pH of about 7.3 , let it settle, absorb the liquid and filter it, and wash it with clean water for 2-3 times. After the liquid, filtrate and lotion are collected, it can be used as green fertilizer. Stir the filter residue, add solution $\mathrm{b}$ to $\mathrm{pH}$ stable at about 11.5, then filter, wash with clean water for $3 \sim 5$ times, collect the filter residue after drying. Filtrate and washing solution are concentrated, $\mathrm{pH}$ is adjusted to about 4 with hydrochloric acid, and then mixed with basic aluminum chloride, which is used as sewage purification agent.

\section{Conclusion}

The waste liquid of COD determined by potassium dichromate method is treated by reduction, neutralization and other measures and the useful substances are recovered, which not only reduces the environmental pollution, but also recovers the resources. It has certain reference value for both analytical chemistry teaching and analytical application practice.

\section{References}

[1] Water and wastewater monitoring and analysis methods [M]. 4th edition. Beijing: environmental science press, 2002, 210-213.

[2] Technical method of environmental impact assessment [M]. Beijing: China environmental science press,2007, 220-232.

[3] GB/ t11914-1989, determination of chemical oxygen demand for water -- dichromate method [S].

[4] Tong s 1. Recovery and utilization of silver in COD wastewater [J]. Journal of liaoyang petrochemical college, 1997,13 (4) : 10-14.

[5] Li fuxiang, cheng yan. Precipitation - neutralization - co-precipitation treatment of COD $\mathrm{Cr}_{\mathrm{r}}$ determination waste liquid [J]. Journal of liaodong university (natural science edition) 2009,16 (4) : 302-305.

[6] Huang $\mathrm{f}$ z, zhu z q. Disposal and comprehensive utilization of waste liquid for COD determination by potassium dichromate method [J]. Pollution control technology, 2008, 21 (3) : 94-95. (in Chinese)

[7] Tao $1 \mathrm{y}$. Design of wastewater treatment scheme for determination of COD by potassium dichromate method [J]. Journal of jinzhou medical college, 2002, 23 (2) : 25-26. (in Chinese) 